Research Article

\title{
Behaviour of Textile-Reinforced Concrete Beams versus Steel-Reinforced Concrete Beams
}

\author{
Fahed Alrshoudi \\ Department of Civil Engineering, College of Engineering, King Saud University, Riyadh 12372, Saudi Arabia \\ Correspondence should be addressed to Fahed Alrshoudi; falrshoudi@ksu.edu.sa
}

Received 2 November 2020; Revised 20 January 2021; Accepted 27 January 2021; Published 19 February 2021

Academic Editor: Paul Awoyera

Copyright (C) 2021 Fahed Alrshoudi. This is an open access article distributed under the Creative Commons Attribution License, which permits unrestricted use, distribution, and reproduction in any medium, provided the original work is properly cited.

\begin{abstract}
There has been a rising interest in utilising textile reinforcement such as carbon tows in constructing concrete components to enhance the performance of conventional reinforced concrete. Textile-reinforced concrete (TRC) has been used as a construction material mostly as primary reinforcement. However, the structural performance of TRC members has not been investigated in depth. Therefore, to better understand TRC beams' behaviour under bending load, a widespread experimental investigation was conducted. The results of tensile stress-strain, load-deflection, moment-curvature, and tension stiffening behaviours of TRC beams were associated with conventional steel-reinforced concrete (SRC) beams. In this study, the four-point bending and tensile strength tests were performed. The results revealed that, unlike the stress-strain behaviour observed in steel, textile reinforcement does not exhibit yielding strain. The flexural behaviour of TRC beams shows no similarity to that of SRC beams at postcracking formation. Besides, the moment capacity and tension stiffening of TRC beams were found $56 \%$ and 7 times higher than those of SRC beams, respectively. Therefore, in light of these results, it can be said that TRC beams behaviour differs from that of SRC beams.
\end{abstract}

\section{Introduction}

Concrete is the main construction material, and it is considered a brittle material, owing to its low tensile strength and energy absorption. Concrete components such beams are mainly exposed to impact loads and bending $[1,2]$. Consequently, higher resistance against deformation and impact loads is essential for concrete components used as structural members. Therefore, to improve concrete properties, additional materials are vital to developing the energy absorption and deformation of concrete [3]. In this regard, researchers have recommended the inclusion of short fibres such as steel and polymeric fibres into concrete mixture [4]. Fibre-reinforced concrete (FRC) is a type of concrete mix that comprises cement, coarse and fine aggregates, and short fibres that are arbitrarily dispersed in the fresh mixture. FRC has been used to strengthen and repair concrete members that have deteriorated due to corroded steel reinforcement. The fibres develop the ductility, energy absorption, tensile, and flexural strengths of the concrete mixture [5]. Besides, FRC with polymeric base fibres can be used in steel-reinforced concrete (SRC) to avoid corrosion in ordinary reinforced concrete [6].

Moreover, the utilisation of textile fibres in concrete to produce the textile reinforced concrete (TRC) has been developed and considered a new composite material used as construction material [7]. The textile fibres such as glass and carbon fibres are typically alkali-resistant, which consist of multifilament roving. TRC beams have significant advantages over conventional FRC, as they can be used in the existence of stresses [8]. According to Papanicolaou and Papantoniou [9], the TRC can be fully utilised in concrete components, as it can be located in the required places such as at the location in line with the tensile stresses with the adequate quantities, while short fibres in FRC are randomly dispersed and oriented in concrete mixture and hence less efficient. Additionally, due to fibres' random positioning in conventional FRC mixes, the short fibres are not entirely effective in controlling the crack formation, strengthening, and stiffening of the concrete components. Besides, the strength in the compression zone of beams is not 
considerably influenced by the addition of short fibres. The strength of textile reinforcement under tension is equivalent to that of steel reinforcement $[10,11]$.

Researchers have found that the reinforcement of concrete components with textile fibres is more efficient and can considerably increase the deformation performance and energy absorption of structural members [12]. In this regard, Häußler-Combe and Hartig [13] reported that the stressstrain performance of TRC is similar to SRC. Nevertheless, the TRC exhibits very little, if any, plasticity; hence, failure is brittle and without much warning; this is different from the ultimate behaviour witnessed in most steel-reinforced beams. Moreover, Graf et al. [14] and Shi-Lang and He [15] stated that, unlike the steel bars, the cross section of the roving is nonhomogeneous along the length of the textile reinforcement, whilst that of a steel bar is consistently homogeneous. However, the behaviour of TRC has not been thoroughly investigated, and more data is required before it can be safely used. Therefore, this work carried out a set of experiments to examine the performance of concrete beams reinforced with textile fibres and compared them with SRC beams.

\section{Materials and Methods}

2.1. Textile Reinforcement. In this study, the multifilament carbon fibre (FORMAX, UK) with various lengths were used as fibrous reinforced materials and then were cut into the desired length based on the size of beams. The fibres having a weight of $10 \mathrm{~g} / \mathrm{m}^{2}$, filament diameter of $7 \mu \mathrm{m}$, and tensile strength of $4000 \mathrm{MPa}$ were used. The appearance of the carbon tows are revealed in Figure 1. Table $1 \mathrm{dem}-$ onstrates the tow properties that are provided by the manufacturer.

2.2. Concrete Proportion. The estimated materials for each cubic meter of concrete are given in Table 2. In this study, type I ordinary Portland cement (OPC) with a Blainespecific surface area of $3990 \mathrm{~cm}^{2} / \mathrm{g}$ and a specific gravity of 3.15 was used. The slump test of fresh concrete was carried out following the specifications of BS EN 12350-02, and it was recorded as $110 \mathrm{~mm}$. Cubic samples with $100 \mathrm{~mm}$ sides following the specifications of BS EN 12390:2-09 and BS EN 12390:3-09 were used for the compressive strength test. The normal concrete mix's average compressive strength was $85 \mathrm{MPa}$ with a standard deviation of 6.5 MPa. After concrete preparation, the fresh concrete was poured into the designed formworks up to a depth of $3 \mathrm{~cm}$. The textile reinforcements with the desired lengths were laid and located at the proper position into the beams. After proper positioning of textile reinforcements, the beams were filled with concrete and completed the finishing process. Besides, a similar procedure was carried out for the steel-reinforced concrete beams. After the casting procedure, the beam specimens were covered and left for 24 hours, and then demoulded and cured at room temperature of $20 \pm 2^{\circ} \mathrm{C}$ and $100 \%$ relative humidity for 28 days.

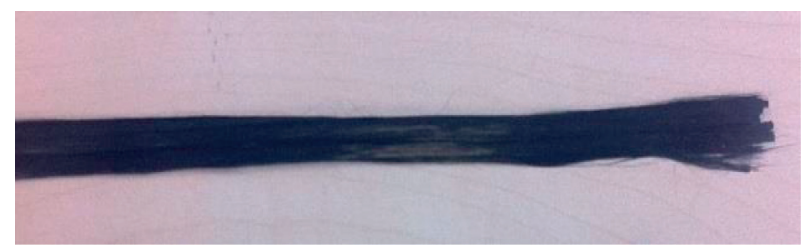

FIgURE 1: Carbon textile reinforcement unidirection $50 \mathrm{k}$.

Table 1: Properties of carbon textile fibres supplied by the manufacturer.

\begin{tabular}{lc}
\hline Properties & Tow, $50 \mathrm{k}$ \\
\hline Filament diameter $(\mu \mathrm{m})$ & 7 \\
Number of filaments $(\mathrm{k})$ & 50 \\
Fabric weight $\left(\mathrm{g} / \mathrm{m}^{2}\right)$ & 130 \\
Tensile strength, $f_{f}(\mathrm{MPa})$ & 4000 \\
Modulus of elasticity, $E_{f}(\mathrm{MPa})$ & 235000 \\
\hline
\end{tabular}

TABLE 2: The concrete proportions of normal concrete.

\begin{tabular}{lc}
\hline Concrete mixture & Mix $\left(\mathrm{kg} / \mathrm{m}^{3}\right)$ \\
\hline Cement & 504 \\
CA 3/8" $(10 \mathrm{~mm})$ & 1108 \\
Sand & 683 \\
Water & 177 \\
W/c & 0.35 \\
Superplasticizer $(\mathrm{SP})$, litre & 7 \\
Slump test $(\mathrm{mm})$ & 110 \\
Compressive strength $(\mathrm{MPa})$ & 85 \\
\hline
\end{tabular}

2.3. Tensile Strength of Tow and Steel. In this study, the textile carbon fibres were tested to evaluate the tensile strength, modulus of elasticity, and elongation using a universal tensile testing machine, with $300 \mathrm{kN}$ capacity. As revealed in Figure 2, the distance between two holders of the testing machine was kept as $17.5 \mathrm{~cm}$. Also, the stroke rate was kept constant as $1 \mathrm{~mm} / \mathrm{min}$. The tensile strength of the steel bars used as reinforcement was attained by using a tensile testing machine (Instron 8500) following the specification of BS 4449:2005. It was found that the tensile strength of the textile reinforcement was lesser than that of the roving (multifilaments) and that the roving was weaker than a single filament. The roving is formed of thousands of filaments, and the textile is formed of rovings in two directions (warp and weft). Generally, the data provided by the manufacturers are related to the single filament. Consequently, to attain the actual tensile strength of tows, it is essential to test the textile filaments used in the main experiments. Nominal textile reinforcement properties are revealed in Table 1 following the datasheet provided by the manufacturing company.

2.4. Four-Point Bending Tests. Beam specimens of size $120 \mathrm{~mm} \times 200 \mathrm{~mm} \times 2600 \mathrm{~mm}$ were cast and cured for 28 days for testing the flexural behaviour, using a ToniPACT 3000 testing machine with $150 \mathrm{kN}$ capacity and a constant loading rate of $0.1 \mathrm{kN} / \mathrm{sec}$. As illustrated in Figure 3, the fourpoint bending test was used to evaluate beams' flexural 


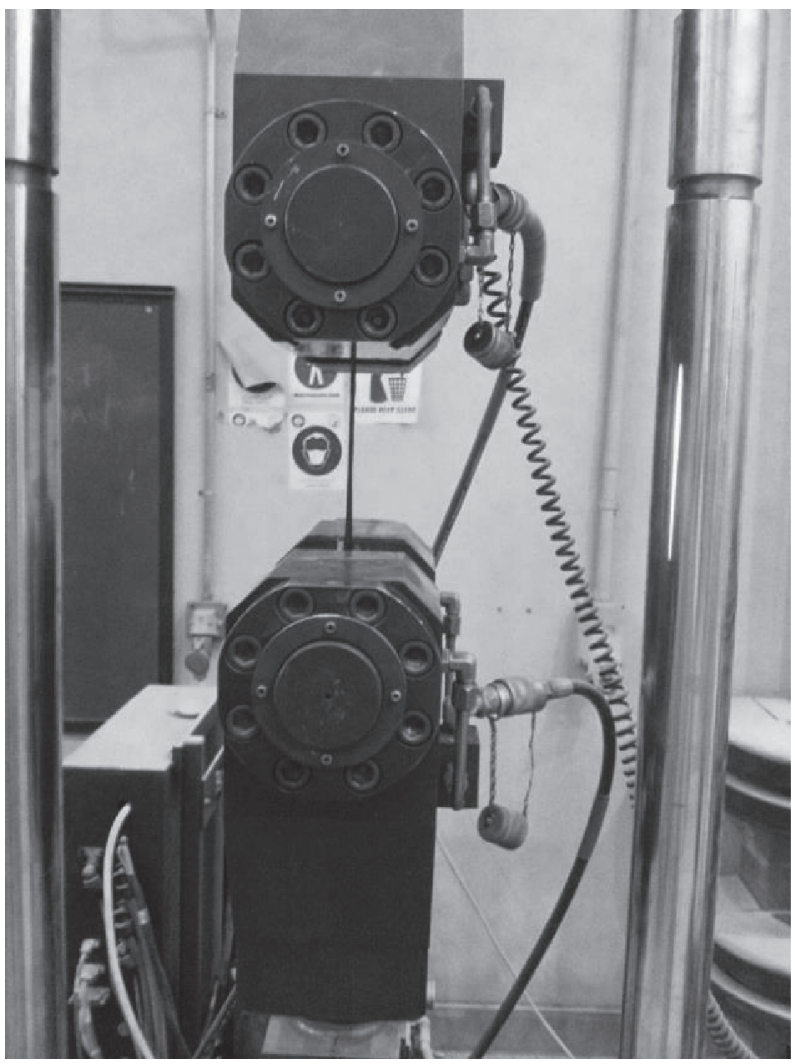

Figure 2: The tensile test setup and elongation of textile fibres.

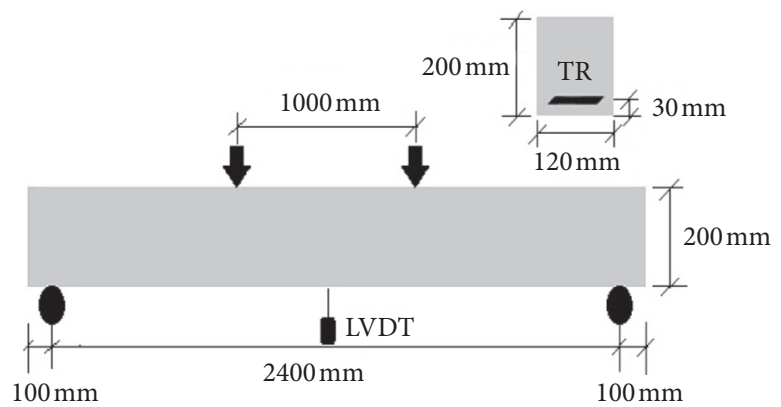

FIGURE 3: Four-point bending test setup of the reinforced beams.

performance. It can be observed that an LVDT was placed at the middle span of beams to measure the deflection at different loads. Three beams were cast and tested for each group, and the average value was noted as the final result. The LVDT was connected to a digital data logger to record the deformation's variation at different loads. As revealed in Figure 4, tow reinforcements were divided into three layers with the constant horizontal spacing between tows as $20 \mathrm{~mm}$. $\mathrm{UT}_{15}$-Anch-3 $\mathrm{L}_{3}-2.6$ stands for 15 tows divided into 3 layers $\left(L_{3}\right)$ and the reinforcement edge was anchored at both ends of the $2.6 \mathrm{~m}$ beam. This has been found to be the optimum layout. Two steel bars with $8 \mathrm{~mm}$ diameter were used to reinforce concrete beams (SRC). The mechanical properties from the manufacturer data sheet were yield strength $f_{y}=500 \mathrm{MPa}$ and yield strain was $\varepsilon_{y}=0.0025$.

\section{Results and Discussion of TRC and SRC Beams}

3.1. Stress-Strain Behaviour. In this study, the carbon textile fibres used as tow tested for tensile strength and the results are illustrated in Figure 5. Overall, ten tow specimens were tested, and the average value of ultimate tensile strength was found as $1550 \mathrm{MPa}$ with a standard deviation of $60 \mathrm{MPa}$. It can be seen that, at the maximum stress of $1550 \mathrm{MPa}$, the strain was found as about 0.021 . The outcomes of the experimental investigations revealed a noteworthy difference amongst the provided tensile strength value of single filament by the manufacture as $400 \mathrm{MPa}$ and those values recoded in those studies. The difference between the obtained results and those given by the manufacture could be due to the number of filaments used in 


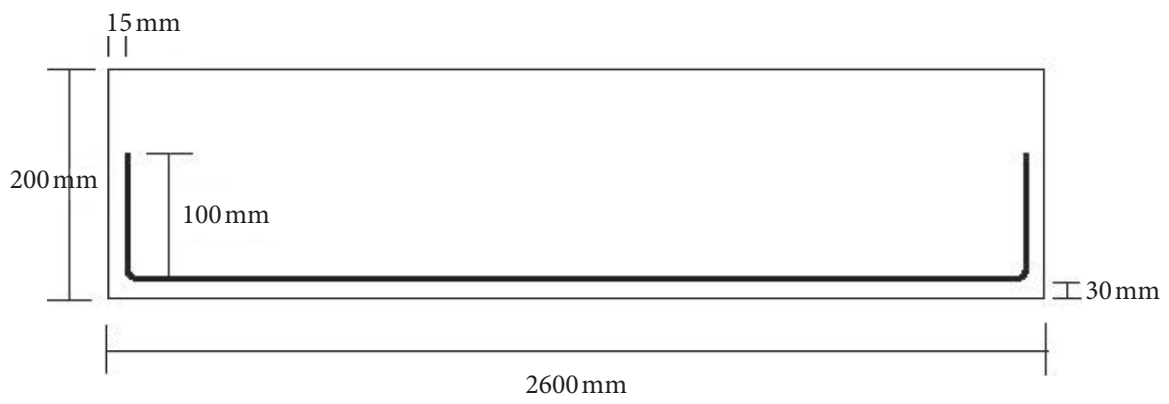

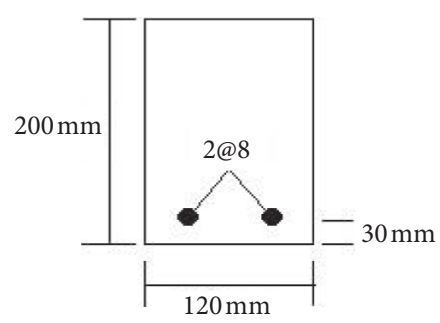

(a)

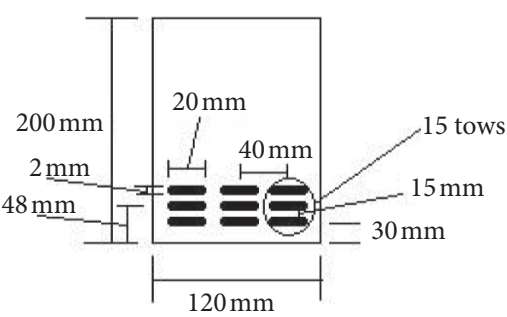

(b)

Figure 4: Reinforcement details of the beams. (a) Steel reinforcement and (b) textile reinforcement.

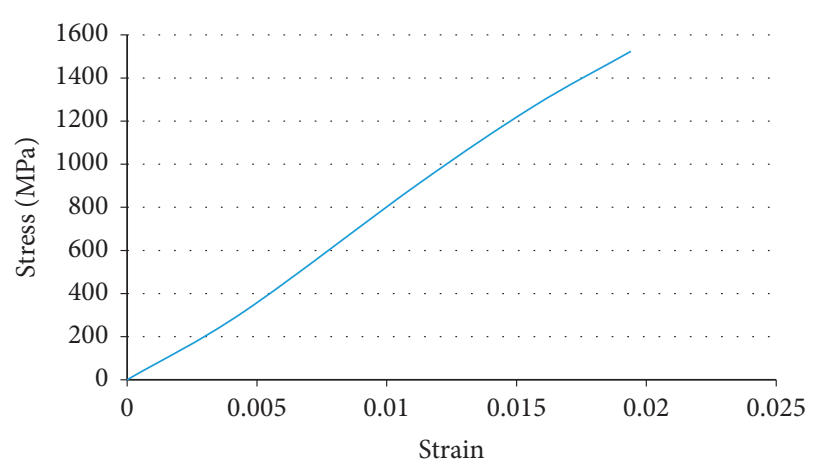

FIgURE 5: Tensile stress-strain curve of textile tows.

each tow. In this regard, Brockmann and Brameshuber [7] stated that a single filament has tensile strength that is higher than that of a multifilament roving, and multifilament rovings are stronger than textiles made thereof. The tensile strength of a single filament is misleading, and, therefore, it should not be considered the tensile strength of a roving or textile reinforcement [16]. The tensile strength reduction might be attributed to the improper cutting of the filaments during preliminary testing, the early fracture of several filaments, and differential elongation between filaments due to the difficulty of the test setup caused by the high number of filaments [17]. Therefore, these problems could lead to premature failure of tows and reduced tensile strength values.

Moreover, the steel bars with $8 \mathrm{~mm}$ diameters used as reinforcement in beams were tested for the tensile strength test. Tensile stress-strain behaviour of steel rebar is illustrated in Figure 6. The average tensile yield strength $\left(f_{y}\right)$ of steel rebar was found as $520 \mathrm{MPa}$ with the yield strain $\left(\varepsilon_{y}\right)$ of 0.00255 . It can be seen that, at yielding strength, the steel bars exhibit high deformation at nearly the same load. From the obtained results revealed in
Figures 5 and 6 , it can be observed that, in textile tows unlike steel reinforcement, the nature of deformation was elastic up to failure and there is no yield plateau. The tensile strength of carbon tows is almost three times greater than that of steel reinforcement, and the failure yield of the tow is also higher than the failure strain of the steel by nearly four times. These results demonstrate the favourable properties of the tow textiles over steel reinforcement, particularly in concrete components such as beams highly affected by deformation [18].

3.2. Load-Deflection Behaviour. As shown in Figures 3 and 4 , the textile reinforcement $\left(A_{f}\right)$ and steel reinforcement $\left(A_{s}\right)$ areas of $92.3 \mathrm{~mm}^{2}$ and $100.5 \mathrm{~mm}^{2}$ were used to reinforce the beams. The beam specimens were tested under bending loads, and the load-deflection behaviour of beams reinforced with steel bars (SRC) and carbon tows ( $\left.\mathrm{UT}_{15}-\mathrm{Anch}-3 \mathrm{~L}_{3}-2.6\right)$ is illustrated in Figure 7. From the obtained results, it can be observed that the beams reinforced with carbon tows performed better than those reinforced with steel bars in terms of ultimate flexural load capacity. For example, the strength capacity of $\mathrm{UT}_{15}$-Anch-3 $\mathrm{L}_{3}-2.6$ beams was found to be about $60 \%$ higher than those of SRC beams. Besides, TRC beams exhibit higher stiffness than those of SRC beams, which might be owing to the higher modulus of elasticity of the tows, delaying the crack formation in the beams $[19,20]$.

Moreover, the results revealed that the SRC beams performed more plastic at postcrack formation. In $\mathrm{UT}_{15^{-}}$ Anch- $3 \mathrm{~L}_{3}-2.6$ beams, the ultimate deflection was about $40 \%$ lower than that of SRC beams. The higher ultimate deflection in the SRC beams could be due to the steel bars' yielding deformation. It can be observed that the ultimate strength of the SRC beam becomes stable after reaching yielding strength until the failure occurred. This continued ultimate strength resulted from the steel's ultimate strain, which 
prevents the beams from sudden collapse [21]. Additionally, in TRC beams, the strength was continually increased while the primary cracks occurred. This rise in strength was continued until the failure was controlled by the ultimate strain of the carbon tows.

It was also found that, in TRC beams, the deflection under service loads was comparatively $50 \%$ lesser than that recorded for the SRC beams, while a similar slope was noted for both types of beams at the service loads. It is interesting to note that total ten primary cracks at the load of $20 \mathrm{kN}$ were formed in the SRC beam with the average crack spacing of $11.3 \mathrm{~cm}$ and the crack formation was stabilised at about $85 \%$ of ultimate load and $20 \%$ of ultimate deflection. In TRC beams, a total of 13 cracks were formed at the load of $26 \mathrm{kN}$ with the crack spacing of $9 \mathrm{~cm}$ and the beams were entirely stabilised at approximately $70 \%$ of ultimate load and $30 \%$ of ultimate deflection.

3.3. Moment-Curvature Behaviour. Figure 8 illustrates the experimental results of moment curvature for both TRC and SRC beams. From the obtained results, it can be observed that the SRC beams exhibited more plasticity, particularly after yielding in comparison with the TRC beams. Nevertheless, the moment capacity of TRC beams was found higher than those of SRC beams. The results revealed that, in both TRC and SRC beams, the moment-curvature behaviour is comparable until the cracking point of the SRC. However, TRC beams exhibited a higher stiffness than that of SRC beams at the cracking formation region. It was found that at the yielding point, which was lesser than $8 \mathrm{kN} \mathrm{m}$, the curvature of TRC beams is about $50 \%$ lesser than that of the SRC beams.

It can be detected that, at the same load, the ductility of SRC beams was higher than those of TRC beams, while, in TRC beams, the stiffness was found higher than those of SRC beams. Besides, the higher stiffness results in a constant rise in beams' strength capacity with a rise in ductility until the failure occurred [22]. At serviceability load, the TRC beam shows higher stiffness, which indicates the lower curvature at the same moment compared to the SRC beams, by more than $50 \%$, which can be accounted for by the high modulus of elasticity postcracking and also the higher moment of inertia. The growth of cracks in the TRC beams was noticeably lower than those of SRC beams.

Moreover, at the ultimate load, TRC beams' curvature was found to be about $37 \%$ lower than that of SRC beams. However, the ultimate strength of TRC beams was about $56 \%$ higher than that of SRC beams. Based on the obtained outcomes, it was detected that at the ultimate moment, the curvature of SRC beams has a greater curvature radius than that of TRC beams. This could be attributed to the area moment of inertia of the TRC beam cross section as the area moment of inertia of the SRC beam at the ultimate was lower than the TRC beam cross section [23].

3.4. Tension Stiffening. In this study, the effects of carbon tow on the tension stiffening of the concrete beam were investigated, and the results were associated with SRC beams. Tension stiffening can be defined as the concrete's contribution after cracking in the tension zone to the

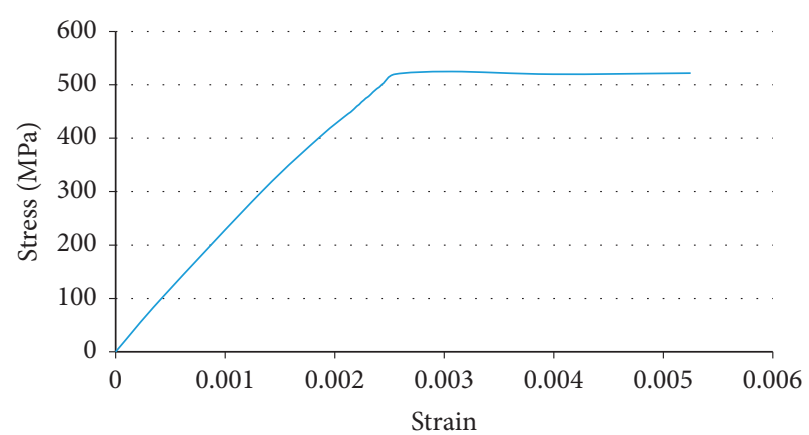

FIgURE 6: Tensile stress-strain curve of steel rebars.

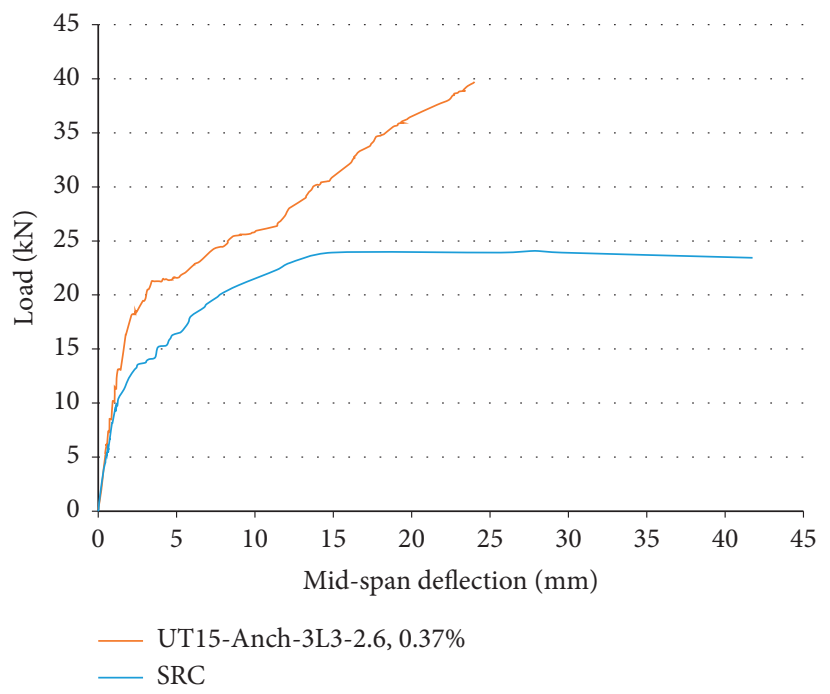

FIgURE 7: Load-deflection curve of TRC and SRC beams.

stiffness of the reinforced section [24]. Tension stiffening of the beam may vary along the span, and the maximum magnitude usually occurred at the cracked section between two primary cracks. Generally, in any beam, the deflection is a function of spans, supports, and loads, divided by flexural stiffness. EI signifies the flexural stiffness of a cross section of a steel-reinforced concrete beam. In beams under load, due to the formation of cracks, the stiffness of a cracked section is reduced due to the reduction in the moment of inertia (I) at the cracked zone. Consequently, the deflection of the beam is considerably affected by the moment of inertia. In general, the stiffness of SRC beams may vary with the bending moment. Therefore, if $M \leq M_{c r}$, the moment of inertia is $I_{g}$, which is the gross moment of inertia, and if $M \geq M_{\mathrm{cr}}$, the moment of inertia is named $I_{\text {eff, }}$ which is the effective moment of inertia, where the beam is along the crack creation phase. Nevertheless, if the beam is entirely cracked, the moment of inertia is called $I_{\mathrm{cr}}$, which is the cracked moment of inertia [25].

The behaviour of the SRC and TRC ( $\left.\mathrm{UT}_{15}-\mathrm{Anch}-3 \mathrm{~L}_{3}-2.6\right)$ with entirely uncracked $\left(\mathrm{EI}_{g}\right)$ and cracked $\left(\mathrm{EI}_{\mathrm{cr}}\right)$ sections are illustrated in Figures 9 and 10. Figure 9 shows that the reduction in the SRC beam's stiffness was begun as the results of 


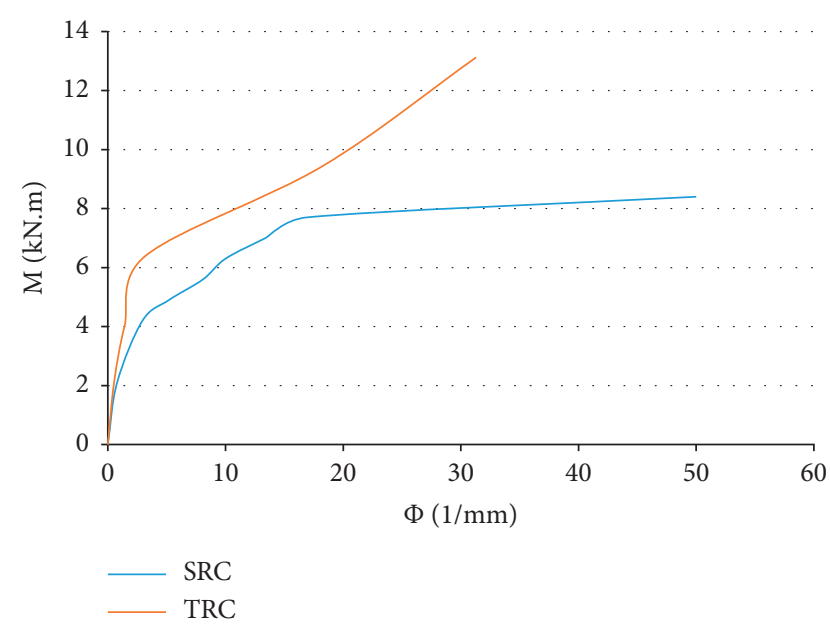

FIgURE 8: Moment curvature of TRC and SRC beams.

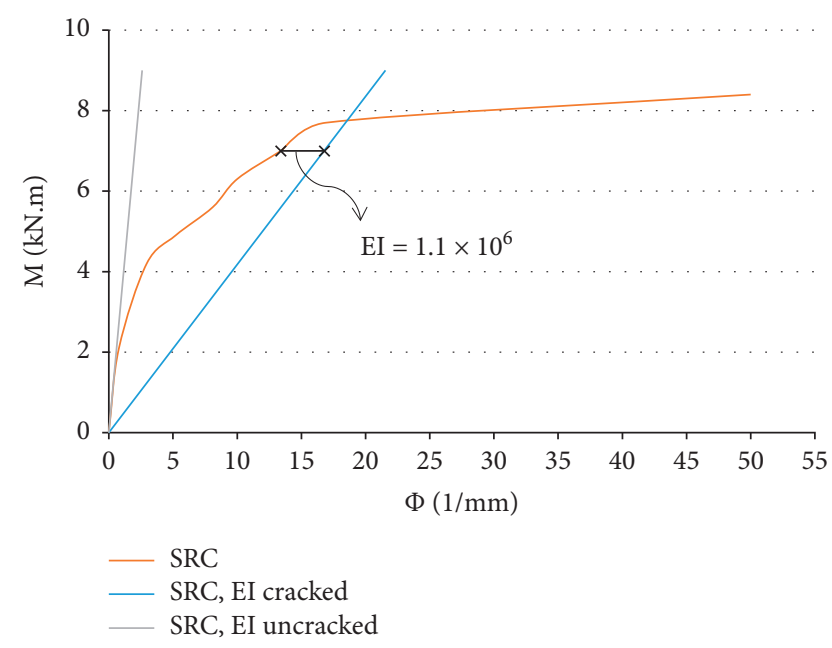

FIgURE 9: Tension stiffening of SRC beams.

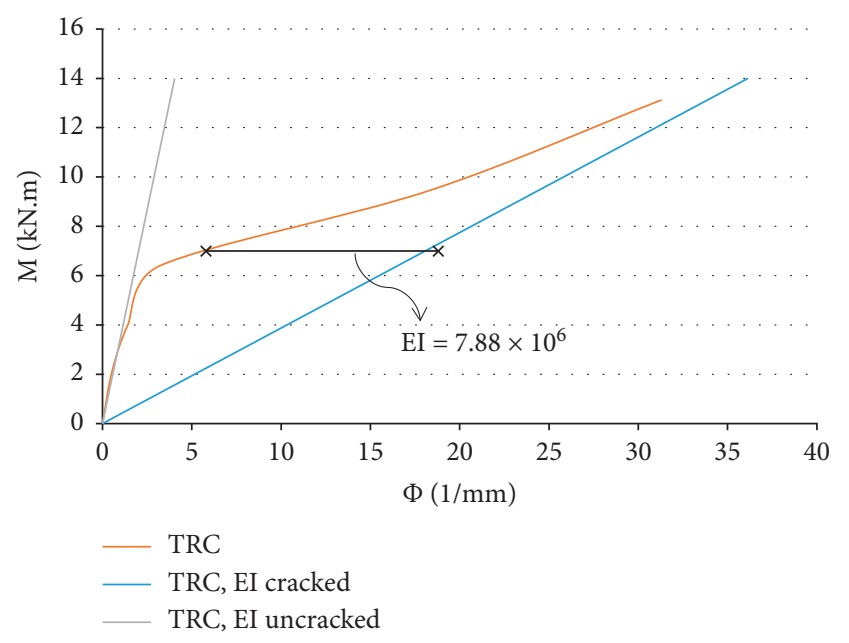

FIgURE 10: Tension stiffening of TRC beams. crack formation at the moment of $4.5 \mathrm{kN} \mathrm{m}$. With a rise at the moment, the stiffness diverged from uncracked to cracked behaviour, which caused an upturn in curvature. Moreover, at the ultimate load, the SRC beams were fully cracked, and the steel reinforcement resisted the tensile stresses. Similarly, Figure 10 displays the reduction in the TRC beams' stiffness at the moment of $6 \mathrm{kN} \mathrm{m}$, when the cracks were initiated. The curvature was increased with the rise in the applied load, and the stiffness was gradually decreased until the failure occurred.

From the outcomes of TRC and SRC beams' tension stiffening behaviour, it was detected that the TRC beams performed better than those of SRC beams. It was found that the tension stiffening of TRC beams at the service moment of $7 \mathrm{kN} \mathrm{m}$ was about 7 times higher than that of SRC beams. Also, it was noted that, at the ultimate moment of about $8 \mathrm{kN} \mathrm{m}$, the involvement of concrete was zero in the SRC beams, while, in the TRC beams, the contribution was significant. Regardless of the formation of secondary cracks at the ultimate load, in TRC beams, the concrete still contributes to resisting the tensile stresses. Consequently, the resistance of concrete against tensile stresses was higher in the TRC beams than SRC beams.

This might be attributed to the smaller spacing amongst the cracks in the TRC beams than SRC beams [24]. The smaller height and depth of cracks in TRC beams were also sufficient. Besides, the greater tension stiffening in the TRC beams is due to the higher tensile strength of the carbon tows than that of steel bars and the layout of the tows, which improved the bond amongst the concrete constituents and the tows. Therefore, this strong bond between concrete and carbon tows resulted in the stiffer matrix and higher tension stiffening in TRC beams [26].

\section{Conclusions}

The effects of carbon tows as reinforcement of concrete beams were examined experimentally, and the outcomes were associated with the steel-reinforced beam. The following conclusions were drawn based on the obtained findings and observations:

(i) Single filament tensile strength is not a reliable value to use in the analysis and design of TRC beams.

(ii) TRC beams' performance in terms of deflection, moment-curvature, and tension stiffening was different from the SRC beams.

(iii) At the yielding point, TRC beams' curvature was found to be about $50 \%$ lesser than that of SRC beams, although the TRC beams resist the applied load continually until failure occurred.

(iv) For the TRC beams, the moment capacity for the same reinforcement area was about 56\% higher than that of SRC beams.

(v) TRC beams were performed better in terms of deflection, and the ultimate deflection was about $40 \%$ lower than that of SRC beams. 
(vi) The tension stiffening behaviour of the TRC beams was about 7 times higher than those of SRC beams, indicating the greater contribution of concrete in the tension zone for the TRC beams.

(vii) The outcomes revealed that, in TRC beams, the surface contact area was higher than SRC beams, which leads to a stronger bond between the carbon and concrete, and, therefore, better performance of TRC beams.

\section{Data Availability}

Data are available on request to the corresponding author.

\section{Conflicts of Interest}

The author declares that there are no conflicts of interest.

\section{Acknowledgments}

The author gratefully acknowledges the financial support of the Researchers Supporting Project (no. RSP-2020/290), King Saud University, Riyadh, Saudi Arabia.

\section{References}

[1] H. Mohammadhosseini, A. S. M. Abdul Awal, and J. B. Mohd Yatim, "The impact resistance and mechanical properties of concrete reinforced with waste polypropylene carpet fibres," Construction and Building Materials, vol. 143, pp. 147-157, 2017.

[2] H. Alabduljabbar, R. Alyousef, H. Mohammadhosseini, and T. Topper, "Bond behavior of cleaned corroded lap spliced beams repaired with carbon fiber reinforced polymer sheets and partial depth repairs," Crystals, vol. 10, no. 11, p. 1014, 2020 .

[3] J. Hegger, N. Will, O. Bruckermann, and S. Voss, "Loadbearing behaviour and simulation of textile reinforced concrete," Materials and Structures, vol. 39, no. 8, pp. 765-776, 2006.

[4] A. S. M. A. Awal and H. Mohammadhosseini, "Green concrete production incorporating waste carpet fiber and palm oil fuel ash," Journal of Cleaner Production, vol. 137, pp. 157-166, 2016.

[5] D. A. Bournas, P. V. Lontou, C. G. Papanicolaou, and T. C. Triantafillou, "Textile-reinforced mortar versus fiberreinforced polymer confinement in reinforced concrete columns," ACI Structural Journal, vol. 104, no. 6, pp. 740-748, 2007.

[6] J. Hegger and S. Voss, "Investigations on the bearing behaviour and application potential of textile reinforced concrete," Engineering Structures, vol. 30, no. 7, pp. 2050-2056, 2008.

[7] T. Brockmann and W. Brameshuber, "Matrix development for the production technology of textile reinforced concrete (TRC) structural elements," in Proceedings of the 2005 3rd International Conference on Composites in Construction, pp. 1165-1172, Lyon, France, July 2005.

[8] A. Brückner, R. Ortlepp, and M. Curbach, "Textile reinforced concrete for strengthening in bending and shear," Materials and Structures, vol. 39, no. 8, pp. 741-748, 2006.

[9] C. G. Papanicolaou and I. C. Papantoniou, "Mechanical behavior of textile reinforced concrete (TRC)/concrete composite elements," Journal of Advanced Concrete Technology, vol. 8, no. 1, pp. 35-47, 2010.

[10] M. Hinzen and W. Brameshuber, "Improvement of serviceability and strength of Textile Reinforced Concrete by using short fibres," in Proceedings of the 4th Colloquium on Textile Reinforced Structures (CTRS4) 2009, pp. 261-272, Dresden, Germany, June 2009.

[11] F. Schladitz, M. Frenzel, D. Ehlig, and M. Curbach, "Bending load capacity of reinforced concrete slabs strengthened with textile reinforced concrete," Engineering Structures, vol. 40, pp. 317-326, 2012.

[12] Z. Cohen, A. Peled, Y. Pasder, A. Roye, and T. Gries, "Effects of warp knitted fabrics made from multi-filament in cementbased composites," in Proceedings of the ICTRC'2006-1st International RILEM Conference on Textile Reinforced Concrete, pp. 23-32, RILEM Publications SARL, Aachen, Germany, January 2006.

[13] U. Häußler-Combe and J. Hartig, "Bond and failure mechanisms of textile reinforced concrete (TRC) under uniaxial tensile loading," Cement and Concrete Composites, vol. 29, no. 4, pp. 279-289, 2007

[14] W. Graf, A. Hoffmann, B. Möller, J.-U. Sickert, and F. Steinigen, "Analysis of textile-reinforced concrete structures under consideration of non-traditional uncertainty models," Engineering Structures, vol. 29, no. 12, pp. 3420-3431, 2007.

[15] X. Shi-Lang and L. He, "Bond properties and experimental methods of textile reinforced concrete," in Proceedings of the ICTRC'2006-1st International RILEM Conference on Textile Reinforced Concrete, RILEM Publications SARL, Aachen, Germany, January 2006.

[16] I. G. Colombo, A. Magri, G. Zani, M. Colombo, and M. Di Prisco, "Erratum to: textile reinforced concrete: experimental investigation on design parameters," Materials and Structures, vol. 46, no. 11, pp. 1953-1971, 2013.

[17] M. Butler, V. Mechtcherine, and S. Hempel, "Experimental investigations on the durability of fibre-matrix interfaces in textile-reinforced concrete," Cement and Concrete Composites, vol. 31, no. 4, pp. 221-231, 2009.

[18] R. Contamine, A. S. Larbi, and P. Hamelin, "Contribution to direct tensile testing of textile reinforced concrete (TRC) composites," Materials Science and Engineering: A, vol. 528, no. 29-30, pp. 8589-8598, 2011.

[19] Y. A. Al-Salloum, H. M. Elsanadedy, S. H. Alsayed, and R. A. Iqbal, "Experimental and numerical study for the shear strengthening of reinforced concrete beams using textilereinforced mortar," Journal of Composites for Construction, vol. 16 , no. 1 , pp. 74-90, 2012

[20] F. Alrshoudi, H. Mohammadhosseini, M. M. Tahir et al., "Drying shrinkage and creep properties of prepacked aggregate concrete reinforced with waste polypropylene fibers," Journal of Building Engineering, vol. 32, Article ID 101522, 2020.

[21] R. Alyousef, T. Topper, and A. Al-Mayah, "Effect of FRP wrapping on fatigue bond behavior of spliced concrete beams," Journal of Composites for Construction, vol. 20, no. 1, p. 04015030, 2016.

[22] K. T. Q. Nguyen, S. Navaratnam, P. Mendis, K. Zhang, J. Barnett, and H. Wang, "Fire safety of composites in prefabricated buildings: from fibre reinforced polymer to textile reinforced concrete," Composites Part B: Engineering, vol. 187, Article ID 107815, 2020. 
[23] Y. Du, X. Zhang, F. Zhou, D. Zhu, M. Zhang, and W. Pan, "Flexural behavior of basalt textile-reinforced concrete," Construction and Building Materials, vol. 183, pp. 7-21, 2018.

[24] S. Khalfallah and D. Guerdouh, "Tension stiffening approach in concrete of tensioned members," International Journal of Advanced Structural Engineering, vol. 6, no. 1, p. 51, 2014.

[25] ACI, ACI 318-11: Building Code Requirements for Structural Concrete and Commentary (318-11), American Concrete Institute, Farmington Hills, MI, USA, 1st edition, 2011.

[26] N. W. Portal, M. Flansbjer, K. Zandi, L. Wlasak, and K. Malaga, "Bending behaviour of novel textile reinforced concrete-foamed concrete (TRC-FC) sandwich elements," Composite Structures, vol. 177, no. 1, pp. 104-118, 2017. 